\title{
CERITA RAKYAT LELIPI SELAN BUKIT SEBAGAI MEDIA PENDIDIKAN ASPEK PALEMAHAN TRI HITA KARANA
}

\author{
I Wayan Aryawan \\ Program Studi Pendidikan Bahasa Indonesia dan Daerah, \\ Fakultas Keguruan dan Ilmu Pendidikan, Universitas Dwijendra \\ aryawan@undwi.ac.id
}

\begin{abstract}
ABSTRAK
Lelipi Selan Bukit merupakan cerita rakyat yang berasal dari Desa Tenganan Pegringsingan, Kabupaten Karangasem, Propinsi Bali. Tujuan penelitian ini yaitu: 1) untuk mengetahui nilai kearifan ekologis yang terkandung dalam cerita rakyat Lelipi Selan Bukit; 2) untuk mengetahui keterkaitan cerita Lelipi Selan Bukit dengan Tri Hita Karana; dan 3) untuk mengetahui perkembangan makna cerita Lelipi Selan Bukit dalam kehidupan masyarakat di Desa Tenganan Pegringsingan. Metode yang digunakan dalam penelitian ini adalah pendekatan kualitatif. Data dikumpulkan dengan studi kepustakaan sedangkan analisis data dilakukan melalui kegiatan reduksi data, penyajian data, serta penarikan kesimpulan/verifikasi data. Hasil penelitian menunjukkan bahwa cerita Lelipi Selan Bukit ini secara tidak langsung telah menjadi benteng bagi kawasan hutan Tenganan Pegringsingan agar tetap terjaga kelestariannya. Cerita ini memberikan dampak baik yang membuat orang-orang tidak berani sembarangan mengeksploitasi hutan. Cerita Lelipi Selan Bukit sebagai kearifan ekologis masyarakat Tenganan Pegringsingan memiliki hubungan yang erat dengan aspek Palemahan falsafah Tri Hita Karana. Dalam perkembangannya perlindungan terhadap hutan itu pun dituangkan kedalam Undang-Undang (awig-awig) Desa Tenganan Pegringsingan yang masih berlaku sampai sekarang.
\end{abstract}

Kata Kunci: cerita rakyat, lelipi selan bukit, palemahan, tri hita karana.

\begin{abstract}
Lelipi Selan Bukit is a folklore originating from Tenganan Pegringsingan Village, Karangasem Regency, Bali Province. The objectives of this study are: 1) to determine the value of ecological wisdom contained in the folklore of Lelipi Selan Bukit; 2) to determine the relationship between the story of Lelipi Selan Bukit and Tri Hita Karana; and 3) to find out the development of the meaning of the Lelipi Selan Bukit story in the community life in Tenganan Pegringsingan Village. The method used in this research is a qualitative approach. The data were collected by means of literature study, while data analysis was carried out through data reduction, data presentation, and drawing conclusions / data verification. The results showed that the story of Lelipi Selan Bukit has indirectly become a fortress for the Tenganan Pegringsingan forest area in order to maintain its sustainability. This story has a good impact that discourages people from exploiting the forest carelessly. The story of Lelipi Selan Bukit as the ecological wisdom of the Tenganan Pegringsingan community has a close relationship with the Palemahan aspect of the Tri Hita Karana philosophy. In its development, protection of the forest was also poured into the Law (awig-awig) Tenganan Pegringsingan Village which is still in effect today.
\end{abstract}

Keywords: folklore, lelipi selan bukit, palemahan, tri hita karana.

\section{PENDAHULUAN}

Lingkungan alam selain merupakan tempat tinggal makhluk hidup, juga merupakan tempat mencari kebutuhan hidup seperti makanan untuk kelangsungan hidup dan kebutuhan terkait upacara dan ritual. Selain itu lingkungan juga dapat membentuk karakter manusia yang mempunyai peran penting dan kompleks dalam pelestarian lingkungan (Santika, 2018). Undang-Undang Nomor 32 tahun 2009 tentang perlindungan dan pengelolaan lingkungan hidup menegaskan bahwa lingkungan hidup merupakan kesatuan ruang 
dengan semua benda, daya, keadaan dan makhluk hidup termasuk manusia dan perilakunya yang memengaruhi alam itu sendiri. Undang-Undang tersebut, mengisyaratkan posisi manusia yang strategis dan menjadi sangat penting dalam keberlangsungan kehidupan manusia dan makhluk lainnya. Dengan kata lain, tingkah laku manusia sebagai kunci perubahan mampu memengaruhi lingkungan alam (Niman, 2019).

Kearifan lokal merupakan wujud dari perilaku masyarakat tertentu sehingga dapat hidup berdampingan dengan alam / lingkungan tanpa harus merusaknya. Kearifan lokal merupakan suatu kegiatan unggulan dalam masyarakat tertentu, keunggulan tersebut tidak selalu berwujud dan kebendaan, sering kali di dalamnya terkandung unsur kepercayaan atau agama, adat istiadat dan budaya atau nilai-nilai lain yang bermanfaat seperti untuk kesehatan, pertanian, pengairan, dan sebagainya. Merujuk pengertian tersebut dapat dijelaskan pula bahwa kearifan lokal sudah mengakar, bersifat mendasar, dan telah menjadi wujud perilaku dari suatu warga masyarakat guna mengelola dan menjaga lingkungan dengan bijaksana (Sufia et al., 2016).

Istilah Tri Hita Karana muncul ke muka umum pada tanggal 11 November 1966, pada waktu diselenggarakan Konfrensi Daerah I Badan Perjuangan Umat Hindu Bali bertempat di Perguruan Dwijendra Denpasar. Tri Hita Karana berasal dari bahasa Sansekerta, yang terdiri dari kata Tri yang artinya tiga, Hita artinya sejahtera dan Karana artinya penyebab. Pengertian Tri Hita Karana atau Tri Hita Karana adalah tiga hal pokok yang menyebabkan kesejahteraan dan kemakmuran hidup manusia. Konsep ini muncul berkaitan erat dengan keberadaan hidup bermasyarakat di Bali (Mahayu, 2015).

Dalam konsep keharmonisan alam (Tri Hita Karana) dijelaskan terdiri dari Parhyangan yang berarti menjaga hubungan harmonis dengan sang pencipta atau Tuhan Yang Maha Esa. sangat sejalan dengan konsep Tri Hita Karana yang dipegang teguh oleh masyarakat Bali dalam menjaga hubungan harmonis dengan sesama manusia, alam dan Tuhan (Priantini,2019). Kemudian konsep Pawongan yang bermakna menjaga hubungan harmonis dengan semua makhluk hidup, khususnya sesama manusia dan yang terakhir adalah Palemahan yang berarti menjaga hubungan yang harmonis dengan alam dan lingkungan (Sudarsana, 2017).

Konsep Tri Hita Karana merupakan kearifan lokal Bali yang perlu dilestarikan untuk mewujudkan keharmonisan dalam kehidupan manusia sehingga tercapai kebahagiaan. Dari ketiga konsep Tri Hita Karana, konsep Palemahan merupakan salah satu konsep yang mengaitkan hubungan manusia dengan alam. Di satu sisi manusia membutuhkan alam di sisi lain alam membutuhkan manusia agar kelestariannya tetap terjaga (Santika, 2021). Dalam pengelolaan lingkungan/alam yang berdasarkan pada nilai filosofis Tri Hita Karana (THK), diharapkan manusia tidak hanya mengejar keuntungan ekonomi semata namun juga mempertimbangkan nilai- nilai ketuhanan atau spiritual dan nilai-nilai kemasyarakatan atau kemanusiaan. Hal ini ditekankan karena sering kali manusia hanya mementingkan keuntungan ekonomi dan sering tidak memperhatikan lingkungan serta nilai sosial budaya lokal (Dalem, 2015). 
Di Bali konsep pelestarian alam dengan kearifan lokal cukup banyak ditemui dari pelaksanaan upacara-upacara adat dan cerita rakyat. Dalam pengembangan karakter anak tidaklah merupakan hal yang mudah, akan tetapi anak perlu ikut berpartisipasi dalam dialog mengenai moral yang terdapat di dalam cerita (Priantini,2019). Salah satu cerita rakyat yang dikaitkan dengan konsep pelestarian alam adalah cerita Lelipi Selan Bukit yang ada di Desa Tenganan, Kecamatan Manggis, Kabupaten Karangasem, Provinsi Bali.

Tujuan penelitian ini yaitu: 1) untuk mengetahui nilai kearifan ekologis yang terkandung dalam cerita rakyat Lelipi Selan Bukit; 2) untuk mengetahui keterkaitan cerita Lelipi Selan Bukit dengan Tri Hita Karana; serta 3) untuk mengetahui perkembangan makna cerita Lelipi Selan Bukit dalam kehidupan masyarakat di Desa Tenganan Pegringsingan.

\section{METODE}

Pendekatan yang digunakan dalam penelitian ini adalah pendekatan kualitatif. Data dikumpulkan dengan studi kepustakaan. Studi kepustakaan merupakan teknik pengumpulan data dengan mencari informasi dari buku literatur, jurnal, peraturan, laporan penelitian, karangan ilmiah, media massa dan sumber-sumber tertulis baik cetak maupun elektronik (Mukhlasin, 2019). Tahapan analisis data dilakukan menggunakan teknik analisis model Miles dan Huberman yaitu mengadakan kegiatan reduksi data, penyajian data, serta penarikan kesimpulan/verifikasi data (Sugiyono, 2019).

\section{HASIL DAN PEMBAHASAN}

Gambaran Umum Desa Tenganan
Pegringsingan

Tenganan Pegringsingan adalah salah satu desa adat yang berada dalam wilayah Desa Tenganan, Kecamatan Manggis, Kabupaten Karangasem. Desa adat Tenganan Pegringsingan terletak kurang lebih $17 \mathrm{~km}$ di sebelah Barat kota Amlapura, ibukota Kabupaten Karangasem, atau sekitar $65 \mathrm{~km}$ ke arah Timur dari kota Denpasar, ibukota Daerah Tingkat I Provinsi Bali.

Masyarakat Tenganan Pengringsingan adalah salah satu bentuk masyarakat Bali Aga, Bali Kuna, atau Bali asli yang masih tersisa, yang mempunyai struktur kebudayaan tersendiri, dan kurang sekali mendapat pengaruh dari kebudayaan Hindu-Jawa yang datang dari Majapahit dahulu. Karena itu, religi orang Tenganan agak berbeda dengan religi orang Bali pada umumnya di luar Desa Tenganan. Agama orang Tenganan adalah Hindu yang menonjolkan peran Dewa Indera, dan masih lebih banyak berdasarkan atas kepercayaan asli Desa Tenganan seperti : (1) percaya adanya roh leluhur yang harus dipuja (ancestor worship); (2) percaya adanya roh-roh lain di sekeliling tempat tinggalnya (animisme); (3) percaya adanya bendabenda atau tumbuh-tumbuhan yang mempunyai jiwa dan perasaan seperti manusia (animatisme); dan percaya adanya kekuatan-kekuatan sakti yang berasal dari benda-benda yang bersifat luar biasa (dinamisme). Selain itu, orang Tenganan juga mengenal kepercayaan yang berkaitan dengan tata letak pekarangan rumah yang dipercaya dapat membawa malapetaka bagi penghuninya (ngapes), dan legenda tentang ular berbisa penjelmaan dari manusia disebut lelipi selan bukit yang menjaga hutan lindung Bukit Kangin (Nurjaya, 2001). 
Kawasan hutan di Tenganan seluas 194 hektar sebagian besar terletak di Bukit Kangin (Timur). Dalam kawasan hutan Bukit Kangin tumbuh subur beraneka jenis pohon seperti sonokeling (Delbergia latifolia), kusambi (Scheichera aliosa), tehep (Arthocarpus elastica), kemiri (Aleurites moluccana), belalu (Albizzia chinensis), durian (Durio zybetinius), pinang (Areca catechon), cempaka (Michelia champaca), lontar (Borassus flabelifer), sirih (Piper betel), dan di sepanjang puncak bukit terdapat hutan pohon enau (Arenga sacchifera) yang menghasilkan nira (tuak). Orang Tenganan memandang hutan lindung Bukit Kangin selain sebagai sumber kehidupan yang menyediakan kayu, buah-buahan, nira, tumbuhan obat-obatan, sumber air, dll. juga dipersepsikan sebagai harta warisan leluhur yang harus dijaga kelestarian dan kesuciannya. Karena itu, kawasan hutan dijaga ketat, dilestarikan, dan dilindungi dengan sistem normatif orang Tenganan yang disebut Awig-awig, yaitu seperangkat norma hukum yang mengatur perilaku warga adat dalam hubungannya dengan leluhur/ Tuhan (tata parhyangan), hubungan antar sesama warga adat (tata pakraman), dan hubungan antara warga adat dengan lingkungan alamnya (tata palemahan), disertai dengan sanksi-sanksi adat yang ditegakkan secara konsisten oleh institusi pemerintahan desa adat yang dipimpin Klian Desa (Kepala Desa) (Nurjaya, 2001).

\section{Sinopsis Cerita Lelipi Selan Bukit}

Zaman dahulu di desa Tenganan pegringsingan ada orang yang bernama I Pasek Tenganan. Diceritakan I Pasek Tenganan mempunyai dua anak gadis. I Pasek Tenganan dibantu oleh seorang pembantu kesayangan yang bernama I Tundung. I Tundung diberikan menggarap tanahnya untuk sumber kehidupannya. Kebun itu terletak di tepi sebelah barat Desa Tenganan (di bukit Tenganan) di daerah Nagasulung. berkat ketekunan I Tundung dan istrinya menggarap kebunnya I Pasek Tenganan maka tanahnya menjadi subur dan hasilnya pun sangat bagus terutama buah pisang dan buahnya sangat besar-besar. buah pisang itulah Sumber penghasilan utama I Tundung di kebun itu. I Tundung adalah orang yang sangat giat bekerja, sehingga tanah yang digarapnya menjadi sangat subur dan menghasilkan hasil kebun yang sangat bagus. setiap kali panen, biasanya I Tundung bersama istrinya datang ke desa yaitu ke desa Tenganan ke rumah I Pasek membawa hasil kebun sesuai apa yang dihasilkan karena kebunnya begitu subur, dan hasilnya sangat bagus, banyak pencuri yang mengintainya, dan I Tundung sering kecurian. Karena sering kecurian I Tundung sangat kesal dengan pencuri itu. karena itu I Tundung berusaha mengintai pencuri itu akan tetapi dalam pengintaian itu, I Tundung dan istrinya tidak pernah berhasil menemui pencuri itu, yang menyebabkan hasil yang biasanya diserahkan kepada I Pasek dihabiskan oleh pencuri. Dengan demikian I Tundung merasa sangat malu kepada I Pasek karena ia tidak pernah lagi membawa hasil kebun ke rumah I Pasek. Dengan keadaan itu I Tundung hampir tiap malam tidak bisa tidur memikirkan hal itu. Mereka sangat jengkel kepada perbuatan Mencuri itu. akhirnya timbul pemikiran mereka untuk memohon kepada Ida Sanghyang Widhi Wasa (Tuhan yang maha kuasa) agar mereka ditakuti pencuri, dan hasil kebunnya tidak dicuri lagi. 
Pada suatu hari (pada hari baik) bulatlah pikiran I Tundung untuk memohon kepada Ida Sang Hyang Widhi Wasa (Tuhan Yang Maha Kuasa) yang ada di Pura Nagasulung Bukit Tenganan. I Tundung datang ke Pura Nagasulung dengan membawa sesajen yang diletakkan di atas sanggah cucuk. di sana itu I Tundung bersemedi memohon kepada Tuhan (Dewata) yang ada di Pura itu agar mengabulkan permohonannya. Di Pura itu mereka lalu bersemedi memohon agar mereka ditakuti pencuri. Begitu mereka memohon, kehadapan-Nya, lalu terdengar suara gaib (Sabda) dari langit yang mana Sabda itu demikian bunyinya "Hai kau Tundung mengapa kau malam-malam di sini tidak mengenal takut?" "Hamba sering sekali kecurian, hamba telah beberapa kali mengintai pencuri, tetapi belum pernah berhasil menemukan pencuri itu" kata I Tundung dalam pertapaan di Pura Nagasulung itu, "lalu apa upaya hamba?" "Kalau sekiranya Betara berikan, hamba meminta agar hamba ditakuti manusia" kata I Tundung. "Kalau kalian mau ditakuti manusia kalian akan berubah rupa menjadi ular dan tidak akan punya teman lagi” begitu kata Sabda itu. I Tundung dan istrinya menyetujui persyaratan itu, dan tidak lama kemudian berubahlah I Tundung dan istrinya menjadi dua ekor ular besar-besar, yang kemudian disebut dengan nama ular Selan Bukit. Akibat perbuatan dan perubahan bentuk rupa itu, maka I Tundung tidak berani lagi datang ke rumah I Pasek di desa, dan I Pasek menjadi penasaran dengan keadaan itu.

Suatu ketika diceritakan I Pasek mengeluh kepada anak gadisnya karena I Tundung lama tidak pernah datang ke rumah I Pasek seperti biasa membawa hasil kebun. I Pasek sangat khawatir dengan keadaan mereka. Apakah mereka sakit, atau bagaimana? keluh I Pasek kepada istri dan anak gadisnya. Setelah lama I Tundung juga tidak datang, kemudian I Pasek menyuruh anak gadisnya untuk datang ke kebun tempat I Tundung tinggal (memondok). Sampai di sana anak gadis itu langsung datang ke pondok I Tundung. Saat itu tampak di pondoknya I Tundung sepi dan tidak ada seorangpun di sana. Lalu anak gadis I Pasek memanggil-manggil nama I Tundung, tetap tidak ada orang yang menyahut. karena tidak ada orang di pondok itu, lalu anak gadis itu pergi berkeliling kebun mencari I Tundung. Sampailah anak I Pasek Itu ke daerah Pura Nagasulung untuk mencari I Tundung. Di sana anak gadis itu lagi memanggilmanggil nama I Tundung. "Tundung, Tundung, Tundung”, begitu anak gadis itu memanggilnya. Tiba-tiba datanglah dua ekor ular besar-besar yang membuat anak gadis itu kaget dan lari ketakutan.

Tanpa berpikir panjang, anak gadis itu langsung lari tunggang-langgang dan kembali ke rumahnya di desa.Sampai di rumahnya anak gadis itu bercerita kepada orang tuanya (I Pasek) tentang apa yang ia lihat di kebun. I Pasek pun berpikir, dan segera pula pergi ke kebun untuk mengetahui apa yang terjadi. Sampai di kebun di pondok I Tundung, I Pasek juga menemukan keadaan yang sepi, tidak melihat siapapun ada di kebun. Di sana I Pasek juga memanggil-manggil nama I Tundung. Tanpa diketahui dari mana datang, tiba-tiba muncul pula ular besar, yang membuat I Pasek ketakutan dan ingin melarikan diri. Begitu I Pasek mau lari, terdengar suara dari I Tundung, "Jero Pasek, Jero Pasek, jangan takut, kami ini adalah I Tundung, penyakap Jero Pasek. Kami telah berubah rupa menjadi ular, karena saat memohon kepada Tuhan di Pura Nagasulung, kami mohon agar ditakuti oleh pencuri”. I Pasek bertanya pula. "Mengapa sampai 
begitu?”. Dijawab oleh I Tundung, “ Kami sangat kesal kepada pencuri, semua hasil kebun dicuri sehingga kami malu kepada Jero Pasek, kami tidak pernah lagi membawa hasil kebun ke rumah Jero Pasek. Karena itulah kami memohon kepada Tuhan, agar kami ditakuti pencuri. Akhirnya kami berubah menjadi ular seperti sekarang”.

Diceritakan, I Pasek memahami keadaan seperti itu, dan tidak marah kepada I Tundung. Selanjutnya I Pasek kembali meminta kepada I Tundung suami istri, agar tetap terus menjaga kebunnya. Di sana I Tundung pun berjanji akan menjaga kebun itu dengan baik, dan mereka berjanji pula, siapapun yang berani mencuri hasil kebun di daerah itu akan menemui bahaya, kecuali keluarga I Pasek. Karena itu, sampai sekarang daerah itu dikenal aman tidak berani pencuri yang mencuri apapun di daerah Tenganan Pegringsingan. Orang-orang takut kepada ular, Lelipi Selan Bukit dan Lelipi Selan Pandan itu, kalau-kalau akan menggigitnya.

Apabila orang yang melanggar, atau mencuri kayu, atau hasil kebun di sana, ular itu tidak akan segan-segan mengejar pencuri itu kemana saja larinya. Pengejaran pencuri itu akan terhenti, kalau sampai harus melewati sungai (air yang mengalir), atau sedang makan. di sini Lelipi Selan Bukit itu hanya seperti manusia, dapat bertanya kepada siapa, apa saja yang ditemui. Pohon, dan rumput pun akan menjawab kalau ditanya. Apabila akan melewati sungai, atau air yang mengalir, pertanyaan ular itu akan dijawab "saya tidak tahu, saya baru datang". Air yang mengalir itu selalu baru datang (mengalir terus). Ular itu pun tidak mau lagi meneruskan pengejarannya. Juga kalau yang bersalah itu ditemui sedang makan, maka Lelipi Selan Bukit pun tidak mau mengganggu, menggigit. Karena ular itu jelmaan manusia, tahu etika, maka ia tidak boleh mengganggu orang sedang makan (Kertiasih, 2018).

\section{Nilai Kearifan Ekologis yang Terkandung Dalam Cerita Lelipi Selan Bukit}

Dari cerita Lelipi Selan Bukit yang telah dipaparkan sebelumnya dapat dilihat bahwa Lelipi Selan Bukit merupakan bagian dari sistem kepercayaan masyarakat Tenganan Pegringsingan. Sistem kepercayaan yang dimiliki oleh masyarakat ini akan senantiasa berpengaruh pada pola pikir dan tingkah laku masyarakat Tenganan Pegringsingan yang nantinya berujung pada cara-cara pengelolaan dan pemanfaatan lingkungan. Lelipi Selan Bukit tanpa disadari telah menjelma sebagai kearifan ekologis yang menjaga kawasan hutan Tenganan Pegringsingan. Memiliki hasil hutan yang melimpah tentu ada saja segelintir orang yang ingin berniat jahat dan mengambil hasil hutan secara serakah. Pada kepercayaannya apabila ada seseorang yang ingin berniat jahat, atau merusak hutan maka ular ini akan muncul dan mencelakai orang yang berniat jahat tersebut. Stigma inilah yang menimbulkan perasaan takut pada warga setempat apabila melanggar itu.

Efek rasa takut akan mitos Lelipi Selan Bukit apabila seseorang merusak kawasan hutan menghasilkan kebaikan bagi alam sekitarnya, kepercayaan tersebut nyatanya telah menghindari kawasan hutan Tenganan dari alih fungsi lahan, dapat dibayangkan apabila kawasan hutan Tenganan Pegringsingan beralih fungsi menjadi kawasan pemukiman, keseimbangan alam akan menjadi terganggu. Flora dan fauna yang tadinya hidup di hutan akan berkurang keberadaannya 
karena keberadaan manusia, selain itu kualitas lingkungan yang tadinya terjaga akan rusak dan bisa menyebabkan bencana seperti longsor. Para leluhur masyarakat Tenganan Pegringsingan telah menyadari betapa pentingnya alam bagi kehidupannya saat itu hingga kehidupan generasinya di masa mendatang, dengan adanya cerita seperti Lelipi Selan Bukit ini secara tidak langsung telah menjadikannya sebagai benteng bagi kawasan hutan Tenganan Pegringsingan agar tetap terjaga kelestariannya (Aditya et al., 2018).

\section{Keterkaitan Cerita Lelipi Selan Bukit Dengan Tri Hita Karana}

Sejak dahulu orang Bali memang dikenal sangat menghargai lingkungannya. Prinsip-prinsip menghargai lingkungan ini tertuang dalam ajaran agama Hindu yang disebut Tri Hita Karana. Kearifan lokal ini telah menjadi landasan filosofis dalam kehidupan masyarakat Bali yang berlandaskan budaya dan dijiwai Agama Hindu.

Pengamalan akan falsafah Tri Hita Karana sebenarnya telah dimiliki oleh para leluhur masyarakat Tenganan Pegringsingan, dengan pengetahuan lokal yang dimilikinya para leluhur masyarakat Tenganan Pegringsingan memiliki kontribusi yang baik dalam upaya menjaga kelestarian kawasan hutannya hingga saat ini. Cerita Lelipi Selan Bukit sebagai kearifan ekologis masyarakat Tenganan Pegringsingan tentu memiliki hubungan yang erat dengan falsafah Tri Hita Karana dalam ajaran Agama Hindu di Bali yang dalam kaitannya dengan alam tentu saja palemahan, yakni hubungan harmonis antara manusia dengan lingkungan alamnya. Leluhur Masyarakat Tenganan Pegringsingan dengan segala kecerdesannya pada masa lampau telah berpikir jauh ke depan mengenai keberlangsungan keadaan lingkungan alamnya. Cerita Lelipi Selan Bukit merupakan suatu bentuk pengetahuan yang diwariskan secara turun-temurun sampai ke generasi saat ini. Cara ini digunakan oleh para leluhur masyarakat Tenganan Pegringsingan dalam upayanya menjaga kelestarian kawasan hutan. Pada perkembangannya, kepercayaan akan Lelipi Selan Bukit masih memberikan dampak yang baik sehingga membuat orang-orang tidak berani sembarangan mengeksploitasi hutan.

Alam merupakan bagian yang tak terpisahkan dari kehidupan masyarakat Tenganan Pegringsingan, dari alam lah masyarakatnya dapat memperoleh berbagai berbagai kebutuhan seharihari, misalnya saja kebutuhan terkait upacara atau ritual. Sebagai Desa Bali Aga (asli) yang memiliki adat dan tradisi yang unik kebutuhan akan sarana ritual tentunya sangat sering diperlukan. Kebutuhan-kebutuhan tersebut akan bergantung pada hasil alam yang diperoleh dari kawasan hutan desa Tenganan Pegringsingan yang diantaranya seperti bambu, kayu, buah- buahan, dan lainnya sebagai sarana kebutuhan penunjang berbagai aktivitas upacara dan ritual di Desa Tenganan Pegringsingan.

\section{Perkembangan Makna Tentang Lelipi Selan Bukit}

Berkembangnya era modern menyebabkan pemikiran masyarakat pun senantiasa ikut berkembanng, hal ini ditandai dengan peningkatan kognitif dalam pemikiran masyarakat. Dilihat dari kacamata pemikiran rasional cerita rakyat Lelipi Selan Bukit merupakan bentuk proteksi leluhur masyarakat Tenganan Pegringsingan terhadap lingkungan hutannya, dengan adanya cerita Lelipi 
Selan Bukit ini diharapakan warga tidak berani sembarangan merusak kawasan hutan. Hutan sebagai salah satu kawasan yang mendukung mata pencarian warga Tenganan Pegringsingan memang sudah selayaknya dijaga keberadaannya. Hutan menyimpan kekayaan alam, cadangan air yang berguna bagi warga desa serta menjaga agar Desa Tenganan Pegringsingan terhindar dari bencana alam seperti longsor. Cerita Lelipi Selan Bukit juga berfungsi sebagai pengingat bagi warga Tenganan Pegringsingan agar selalu berhati-hati saat masuk ke dalam kawasan hutan, karena di hutan terdapat hewan-hewan yang berbahaya. Hewan- hewan seperti ular yang masih menghuni kawasan hutan di Desa Tenganan Pegringsingan dapat dijadikan tolak ukur bahwa kawasan habitanya masih terjaga dengan baik, karena apabila kawasan habitatnya sudah rusak pasti hewan- hewan tersebut mulai sulit ditemukan dikawasan tersebut. Keberadaan ular juga dapat dijadikan sinyal-sinyal suatu peristiwa alam bagi masyarakat Desa Tenganan Pegringsingan, tatkala disaat ular-ular yang secara mendadak turun meninggalkan kawasan hutan menuju desa disaat terjadi kebakaran atau longsor yang terjadi di kawasan tempat hidupnya. Seperti diketahui hewan seperti ular memiliki sensitifitas yang tinggi terhadap gejala-gejala alam yang terjadi di habitatnya.

Dalam perkembangannya perlindungan terhadap hutan itu pun dituangkan kedalam Undang-Undang (awig-awig) Desa Tenganan Pegringsingan, sehingga apabila ada warga yang mencari, menebang kayu /pohon tanpa izin penguasa desa akan dikenai denda oleh desa. Awigawig desa mengenai perlindungan hutan seperti itu, masih berlaku sampai sekarang, suatu tradisi yang berguna bagi desa-desa lainnya di Bali. langkah- langkah serupa tampak penting untuk desa-desa lainnya di masyarakat.

\section{SIMPULAN}

Berdasarkan pembahasan yang telah dipaparkan sebelumnya, simpulan yang dapat diambil dari penelitian ini yaitu cerita rakyat Lelipi Selan Bukit memberikan kepercayaan kepada masyarakat desa Tenganan bahwa jika ada seseorang yang ingin berniat jahat, atau merusak hutan maka ular ini akan muncul dan mencelakai orang yang berniat jahat tersebut. Stigma inilah yang memberikan efek rasa takut kepada warga setempat jika melanggar itu. Efek rasa takut ini menghasilkan nilai kearifan ekologis pada masyarakat Desa Tenganan dimana cerita Lelipi Selan Bukit ini secara tidak langsung telah menjadi benteng bagi kawasan hutan Tenganan Pegringsingan agar tetap terjaga kelestariannya.

$$
\text { Cerita Lelipi Selan Bukit memiliki }
$$
hubungan yang erat dengan falsafah Tri Hita Karana dalam kaitannya dengan hubungan yang harmonis antara manusia dengan alam (palemahan). Leluhur Masyarakat Tenganan Pegringsingan dengan segala kecerdesannya pada masa lampau telah berpikir jauh ke depan mengenai keberlangsungan keadaan lingkungan alamnya sehingga cerita ini memberikan dampak baik yang membuat orang-orang tidak berani sembarangan mengeksploitasi hutan.

Dalam perkembangannya perlindungan terhadap hutan itu pun dituangkan kedalam Undang-Undang (awig-awig) Desa Tenganan Pegringsingan, sehingga apabila ada warga yang mencari, menebang kayu/pohon tanpa izin penguasa desa akan dikenai denda oleh desa. Awigawig desa mengenai perlindungan hutan seperti itu, 
masih berlaku sampai sekarang, suatu tradisi yang berguna bagi desa-desa lainnya di Bali. Langkahlangkah serupa tampak penting untuk desa-desa lainnya di masyarakat.

\section{DAFTAR PUSTAKA}

Aditya, I. K. A. B., Arsana, I. G. K. G., \& Suarsana, I. N. (2018). Nilai Kearifan Ekologis dalam Mitos Lelipi Selahan Bukit Bagi Masyarakat Desa Tenganan Pegringsingan Kabupaten Karangasem Bali. Jurnal Humanis, Fakultas Ilmu Budaya, Universitas Udayana, 22(1), 81-86. https://doi.org/10.24843/JH.2018.v22.101.p12

Dalem, A. A. G. R. (2015). Pengelolaan Lingkungan Berbasis Kearifan Lokal: Studi Kasus Di Bali. Seminar Dan FGD Pengelolaan Lingkungan Berbasis Kearifan Lokal, 1-10.

Kertiasih, N. N. (2018). Mitos Lelipi Selan Bukit Di Desa Tenganan Pegringsingan (J. Atmaja (ed.); 1st ed.). Udayana University Press.

Mahayu, N. P. C. A. (2015). Wacana Kelestarian Alam Cerita Lipi Selan Bukit Pada Masyarakat Adat Tenganan Pegeringsingan. Jurnal Humanis, Fakultas Ilmu Budaya, Universitas Udayana, 11(2), 1-8.

Mukhlasin, A. (2019). Kepemimpinan Pendidikan Di Era Revolusi Industri 4.0. Jurnal Tawadhu, 3(1), 674-692. https://doi.org/10.13140/RG.2.2.30831.59043

Niman, E. M. (2019). Kearifan Lokal Dan Upaya Pelestarian Lingkungan Alam. Jurnal Pendidikan Dan Kebudayaan Missio, 11(1), 91-106.

Nurjaya, I. N. (2001). Pengelolaan Hutan Berbasis Komunitas Adat: Kasus Tenganan Pegringsingan, Bali. Simposium International Jurnal Antropologi Ke-2, 1-17.

Priantini, D.A.M.M.O. (2019). Pengembangan Model Pembelajaran Model Pembelajaran Karakter Berbasis Mesatua Bali Untuk Anak Sekolah Dasar. Widya Accarya, 10(2).

Santika, I. G. N. (2018). Strategi Meningkatkan Kualitas SDM Masyarakat Desa Padangsambian Kaja Melalui Pendidikan Karakter Berbasiskan Kepedulian Lingkungan Untuk Membebaskannya Dari
Bencana Banjir. Widya Accarya, 9(1).

Santika, I. G. N. (2021). Pendidikan Kewarganegaraan (Studi Komparatif Konstitusi Dengan UUD 1945). Lakeisha.

Sudarsana, I. K. (2017). Konsep Pelestarian Lingkungan Dalam Upacara Tumpek Wariga Sebagai Media Pendidikan Bagi Masyarakat Hindu. Jurnal Studi Agama-Agama Dan Lintas Budaya, 2(1), 1-7.

Sufia, R., Sumarmi, \& Amirudin, A. (2016). Kearifan Lokal Dalam Melestarikan Lingkungan Hidup (Studi Kasus Masyarakat Adat Desa Kemiren Kecamatan Glagah Kabupaten Banyuwangi). Jurnal Pendidikan: Teori, Penelitian, Dan Pengembangan, 1(4), 726-731.

Sugiyono. (2019). Metode Penelitian Pendidikan Pendekatan Kuantitatif, Kualitatif dan $R \& D$. Alfabeta.

Winaya, I.M.A., Priantini, D.A.M.M.O. (2019). PENGEMBANGAN MEDIA PEMBELAJARAN BERBASIS MULTIMEDIA INTERAKTIF DENGAN KONSEP TRI HITA KARANA UNTUK PEMBELAJARAN TEMATIK DI SD KELAS III GUGUS 6 KECAMATAN ABIANSEMAL, BADUNG, BALI. Widya Accarya, 9(2). 